\title{
INTERAÇÃO ENTRE PROFESSORA E ALUNOS EM SALAS DE AULA COM PROPOSTA PEDAGÓGICA DE EDUCAÇÃO INCLUSIVA ${ }^{1}$
}

\author{
TEACHER AND STUDENTS' INTERACTION IN CLASSROOMS WITH PEDAGOGICAL \\ PROPOSAL IN INCLUSIVE EDUCATION
}

Simone Cerqueira da SILVA² Maria Salete Fábio ARANHA ${ }^{3}$

RESUMO: correntes teóricas presentes na literatura científica têm demonstrado a importância das relações interpessoais para o processo de construção do conhecimento. É no contexto da interação professor e aluno que se configura a relação entre as necessidades educacionais dos alunos e as respostas pedagógicas a elas disponibilizadas, o que envolve o domínio do conhecimento pelo professor, sua capacitação técnico-científica, a competência de ensinar pesquisando, as características sócio-culturais e o perfil psicológico dos atores sociais envolvidos- professor e aluno. Buscando melhor compreender este universo, elaborou-se este estudo que teve como objetivo descrever as interações ocorridas entre uma professora, e seus alunos, em classes em que se propunha adotar uma prática pedagógica inclusiva. Os dados foram coletados em 2 salas de aula, em escola estadual de Ensino Fundamental, no município de Bauru. O processo de coleta de dados se deu através do registro da realidade de sala de aula em vídeo tape. Optou-se por este método, por permitir a recuperação posterior dos dados. A coleta se deu no transcorrer do 1ํo semestre do ano letivo de 2001. A análise fundamentouse em sistema prévio de categorias, e tratou os dados quantitativa e qualitativamente. Os resultados demonstraram peculiaridades e diferenças nas interações da professora com os seus alunos, em função da presença ou ausência da deficiência. Indicaram, também, que a interação vem demonstrando avanços na prática educacional, no que diz respeito à atenção pedagógica, da professora, ao aluno com deficiência.

PALAVRAS-CHAVE: educação inclusiva; interação entre professor - aluno; necessidades educacionais especiais.

ABSTRACT: theoretical currents present in the scientific literature have demonstrated the importance of interpersonal relationships in the process of knowledge construction. The relationship between the students' educational needs and the available pedagogical responses occurs in the context of teacher-student interaction. Such a relationship involves the teacher's mastery of knowledge, his technic-scientifical capability and ability to teach through research, the socio-cultural characteristics and psychological profiles of the social actors involved - teacher and student. With the goal of searching for a better understanding of this universe, this study was developed and aimed at describing the interactions occurring between a teacher and her students in classrooms in which it was proposed to adopt an inclusive classroom. The data were collected in 2 classrooms in a public primary school in the city of Bauru. The data collecting process was carried out by videotaping the classroom allowing the data to be reviewed later. The taping took place during the first semester of the 2001 school year. The analysis of the data was based on a previously developed system of categories, and the data were dealt quantitative and qualitatively. The results showed peculiarities and differences in the interactions of the teacher with her students, due to the presence or absence of disability. The interaction also demonstrated advances in educational practice regarding the teacher's attention to the student with disability.

KEYWORDS: inclusive education; student-teacher interaction; special educational needs.

\footnotetext{
${ }^{1} \mathrm{O}$ presente estudo se refere a parte da investigação realizada na dissertação de Mestrado intitulada "Interação entre professora e alunos em sala inclusiva", defendida no Programa de Pós-Graduação em Educação, Universidade Estadual Paulista, câmpus de Marília, em 2003.

2 Psicóloga, Mestre em Educação, docente da Faculdade Auxilium de Lins simonecerqueiradasilva@yahoo.com.br

3 Psicóloga, Doutora em Psicologia Experimental, docente aposentada da Unesp-Bauru saranha@travelnet.com.br
} 


\section{INTRODUÇÃo}

O tema da educação inclusiva tem despertado, no meio educacional, angústias e entusiasmos. A mudança de um sistema educacional, que se caracterizou tradicionalmente por ser excludente e segregatório, para um sistema educacional que se comprometa efetivamente a responder, com qualidade e eficiência, às necessidades educacionais de todos, inclusive às dos alunos que apresentam necessidades educacionais especiais, exige um processo complexo de transformação, tanto do pensar educacional, como da prática cotidiana de ensino.

Todo processo de transformação dessa natureza constitui uma mudança de paradigma, o que, geralmente provoca nas pessoas diversas reações, dentre as quais ansiedade, medo, rejeição, resistência, interesse, entusiasmo. Geralmente, constata-se que inicialmente as pessoas começam a mudar o discurso na direção do politicamente esperado e considerado correto, mantendo, entretanto, padrão de comportamento semelhante ao já conhecido.

No caso do tema aqui focalizado, o paradigma da construção de sistemas educacionais inclusivos, em desenvolvimento, requer relações interpessoais que sejam eficientemente acolhedoras para todos, ou seja, que atendam às necessidades educacionais de todos, inclusive dos que apresentam necessidades educacionais especiais.

Para Leontiev (1978, p. 272), a educação é o processo que possibilita a formação do indivíduo através de sua apropriação dos resultantes da história social e sua conseqüente objetivação nessa história.

Nesse sentido, tem-se que é pela educação que o indivíduo se apropria das características do gênero humano. Características que, segundo Duarte (1993, p. 40), foram criadas e desenvolvidas ao longo do processo de objetivação, gerado, a partir da apropriação da natureza pelo homem.

O processo educativo formal, conforme aponta Boneti (1997), ocorre dentro de um espaço real de ação e interação, para enriquecimento da identidade sócio-cultural dos que dele participam, espaço esse chamado escola.

Para Saviani (1991), a função da escola é estender, a todos os seus alunos, o conhecimento elaborado e sistematizado, fundamental para que as pessoas tenham maior liberdade de ação pela assimilação e internalização do conhecimento, a partir do processo de ensino e de aprendizagem.

Considerando não somente os conteúdos acadêmicos, Mello (1997) diz, ainda, que cabe à escola a função de estabelecer padrões de convivência social.

Neste momento histórico da realidade brasileira, o que se espera é o avanço na direção da construção de um sistema educacional que cumpra efetivamente com o proposto pela Lei de Diretrizes e Bases da Educação Nacional (1996), favorecendo a formação de cidadãos críticos e responsáveis, possibilitando 
o acesso ao saber científico e à sua utilização crítica e funcional rotineira, e desta forma, atuando na construção de uma sociedade mais igualitária e humana.

É no espaço da relação entre professor e aluno que a formação do cidadão se realiza, efetivando a missão maior da educação.

Diversos autores têm demonstrado a importância das relações entre o professor e o aluno para o processo de desenvolvimento e de aprendizagem desse aluno.

Para Hinde (1979), uma relação implica em algum tipo de interação intermitente entre duas pessoas, envolvendo intercâmbios durante um período estendido no tempo, tendo as mesmas, algum grau de mutualidade, de modo que o comportamento de uma leva em consideração o comportamento da outra.

Vygotsky (1994) propõe que as funções psicológicas superiores originam-se das relações reais entre indivíduos humanos, já que no decurso do desenvolvimento, as atividades são inicialmente coletivas / sociais (interpsíquicas) para depois se tornarem atividades individuais / propriedades internas do pensamento.

Tomando como pressupostos os conteúdos propostos pelos autores acima citados, entende-se as interações e a relação entre o professor e seus alunos variáveis essenciais no processo bi-direcional de construção da aprendizagem e do desenvolvimento humano.

Salvador (1994), referindo-se ao contexto da sala de aula, destaca que a unidade básica de análise deixa de ser a atividade individual do aluno e passa a ser a atividade articulada e conjunta do aluno e do professor em torno da realização de tarefas escolares. Constata-se, então, que os sujeitos, professor e aluno, são os atores dessa entrelaçada teia de relações que permeia a instituição escolar e que se apresenta como o fio da meada do processo educacional.

\section{Para Aranha e Laranjeira (1995, p.9)}

[...] é preciso estabelecer, sob novas bases, a relação entre o professor e o aluno, de modo que se repense ambos os papéis, refletindo sobre a bi-direcionalidade e a interdependência que configuram as relações pessoais, para que nos fiquem claras as suas conseqüências.

Os estudos sobre a relação entre professor e aluno nem sempre foram tratados a partir do princípio da reciprocidade, da mutualidade e bi-direcionalidade.

Carvalho (1986) também se dedicou à análise da literatura sobre a relação entre professor e aluno, e constatou que todos os trabalhos enfatizavam que o professor era o elemento que mais falava, e o comportamento do aluno influenciava de maneira diversificada o comportamento do professor.

Por outro lado, posteriormente, Machado (1987) considerou que as pesquisas não privilegiavam a influência do aluno, realçando somente o poder 
que o professor tinha sobre ele, e que, embora os conceitos de interação e reciprocidade fossem referidos, havia uma certa inconsistência aí embutida.

Em 1990, Gil revisou diferentes pesquisas realizadas sobre as relações entre professor e aluno, e verificou a existência de dois grandes grupos de trabalhos que se distinguem pela ênfase dada ora ao rendimento do aluno, e ora às características da interação entre professor e aluno. A autora ainda enfatiza que, embora tais estudos considerassem a interação entre professor e aluno como objeto de estudo, a maioria tratava apenas da influência do comportamento verbal do professor sobre o aluno.

A consideração da relação enquanto sistema requer um deslocamento de foco de análise, na direção de um olhar bi-direcional, no qual o aluno influencia o processo de ensino e é por este influenciado. O professor deixa de ser o único responsável pelos resultados alcançados no processo de ensino e de aprendizagem, e constata-se que o que o aluno faz, exerce influência sobre a ação do professor.

Faz-se necessário salientar aqui o deslocamento do foco de análise, deixando de centrar-se no sujeito, unilateral, para centrar-se na relação, contexto bi-direcional e multideterminado.

Conforme a literatura citada, são escassos os estudos que consideram o fator da mútua determinação entre professor e aluno. Faz-se necessário então, compreender como funciona e quais são os papéis desempenhados nessa relação.

No que se refere ao seu funcionamento, Aranha e Laranjeira (1995) mencionam que a relação entre o professor e o aluno está configurada por uma assimetria, tanto no que se refere ao nível de escolaridade, quanto à experiência de vida, habilidades sociais e complexidade intelectual. Diferenças essas, que pontuam os diferentes papéis que ambos exercem.

Quanto ao papel do professor, as autoras consideram que um professor, para cumprir o seu papel pedagógico, precisa ser um profissional-cidadão, capaz do uso do exercício da consciência crítica e do domínio efetivo do saber que socializa na escola.

É fato que o modo de ser do professor, seu jeito de pensar, agir e sentir repercutirá no comportamento dos alunos, bem como a imagem e a concepção que o aluno tem do professor irá interferir na ação do professor.

A exigência de educação continuada vem se acentuando desde 1996, com a promulgação da Lei de Diretrizes e Bases da Educação Nacional, que reconhece a diversidade no contexto escolar.

A construção de uma sociedade inclusiva é de fundamental importância para o desenvolvimento e a manutenção de um estado democrático.

No âmbito da educação, a opção política pela construção de um sistema educacional inclusivo vem coroar um movimento para assegurar a todos os cidadãos, inclusive aos com deficiência, a possibilidade de aprender a administrar 
a convivência digna e respeitosa numa sociedade complexa e diversificada (ARANHA, 2002).

A escola se torna inclusiva à medida que reconhece a diversidade que constitui seu alunado e a ela responde com eficiência pedagógica. Para responder às necessidades educacionais de cada aluno, condição essencial na prática educacional inclusiva, há que se adequar os diferentes elementos curriculares, de forma a atender as peculiaridades de cada um e de todos os alunos. Há que se flexibilizar o ensino, adotando-se estratégias diferenciadas e adequando a ação educativa às maneiras peculiares dos alunos aprenderem, sempre considerando que o processo de ensino e de aprendizagem pressupõe atender à diversificação de necessidades dos alunos na escola (BRASIL, 1999).

A educação para todos implica, portanto, um sistema educacional que reconhece, respeita e responde, com eficiência pedagógica, a cada aluno que nele se encontra inserido.

A Educação Especial vem contribuir nesse processo, como uma modalidade de ensino que serve a todas as demais modalidades e níveis de escolarização. Responsável especialmente pelo segmento populacional que apresenta necessidades educacionais especiais, deve tanto atender necessidades específicas e peculiares do aluno, como também oferecer suporte técnico-científico ao professor da classe regular que o atende.

Pensar na Educação Inclusiva como uma possibilidade de construção de uma sala de aula melhor, na qual alunos e professores sintam-se motivados a aprender juntos e respeitados nas suas individualidades, parece que realmente pode vir a ser um progresso na história da educação brasileira.

No processo de construção de uma classe inclusiva, as relações entre professor e aluno surgem como elemento de fundamental importância, já que é no contexto das relações que o respeito e a atenção pedagógica flexível e individualizada vão se efetivar.

Sabe-se que desde que o movimento pela construção de sistemas educacionais inclusivos foi se fortalecendo, inclusive amparado legalmente, alunos com deficiência começaram a ser matriculados e a freqüentar classes regulares no ensino comum. A inserção destes alunos nas classes regulares, entretanto, não garantem, por si só, uma prática inclusiva de ensino.

Assim, entende-se importante investigar como estão se dando as relações nesse contexto. Existe diferença na relação entre professor e aluno, quando o aluno tem ou não uma deficiência? As características dessas relações afetam o processo de ensino e de aprendizagem?

O estudo dos aspectos acima apontados não se mostrou freqüente na literatura científica pesquisada, já que não se constatou nenhuma publicação 
realizada no período de 1990 a 2001, em pesquisa bibliográfica realizada em 34 periódicos, 4.697 artigos (SILVA, 2003).

Em 2002, Braga (2002) investigou as interações sociais entre uma professora não especialista e um aluno autista, em ambiente regular considerado inclusivo. A autora utilizou o recurso da filmagem, usando uma filmadora assentada em tripé, com o foco direcionado diretamente sobre o aluno autista. Para a análise dos dados, a autora utilizou um sistema de categorias, adaptação de sistema desenvolvido por Aranha (1991). As conclusões obtidas pela autora confirmaram alguns dados já comentados anteriormente e elucidaram outros, até então não apontados pela literatura.

A autora confirmou que a professora foi quem manteve o controle do início das interações, e que muitas das iniciativas do aluno autista sugeriram a intenção de obter aproximação, atenção e reconhecimento da professora.

Na década de 80, Dorval, Mckinney e Feagans (1982), estudando sobre a relação entre o professor e seus alunos, apontaram que o professor iniciava mais interações com os estudantes que tinham dificuldade de aprendizagem do que com os alunos que obtinham média, mas que esse início de conversação se referia à falta de atenção ou infração de regras por esses alunos.

Confirmando esses apontamentos, Siperstein e Goding (1985) ao estudarem a interação entre o professor e seus alunos, deficientes e não deficientes, mostraram que as iniciativas e respostas dos professores, para os estudantes com deficiência, foram mais negativas e corretivas do que com os estudantes sem deficiência.

No ano posterior, Slate e Saudargas (1986) evidenciaram que os estudantes com dificuldade de aprendizado recebiam mais contatos individualizados com o professor, mas esses contatos diziam respeito ao seu engajamento em outras atividades, diferentes da atividade didática; logo, o tempo das atividades acadêmicas com os alunos com deficiência não era significativo, ao contrário do tempo despendido com os alunos que obtinham média.

Tais estudos indicam as problemáticas vivenciadas no contexto de sala de aula, especialmente nas relações entre alunos e professor, e o quanto essas relações podem prejudicar ou impedir a eficiência do funcionamento que se almeja na educação inclusiva.

A partir da preocupação com o discurso inclusivo que tem permeado o debate social e acadêmico, entendendo a relação entre o professor e o aluno como uma importante via de mediação da construção do conhecimento e da aprendizagem e norteadas pelos resultados acima expostos de poucos estudos realizados acerca dessa temática, elaborou-se este estudo, tendo por objetivo caracterizar a relação entre professora e alunos, em uma sala de aula institucionalmente considerada inclusiva, em unidade escolar da rede pública de ensino, no Estado de São Paulo. 


\section{Método}

Foram participantes deste estudo 2 professoras e seus respectivos alunos. A professora A, que lecionava na turma A, tinha, em sala de aula, 7 alunos do sexo masculino e 14 do sexo feminino. A faixa etária desses alunos era de 8 a 13 anos. A professora B, que lecionava na turma B, tinha, em sala de aula, 12 alunos do sexo masculino e 15 do sexo feminino. A faixa etária desses alunos era de 9 a 17 anos.

Na turma A, 2 alunos tinham deficiência mental e na turma B, 3 alunos tinham deficiência, sendo: 1 com deficiência mental, 1 com deficiência mental e física e 1 com deficiência auditiva e física. Os demais alunos não apresentavam indicação nem diagnóstico formal de deficiência.

Os dados foram coletados em 2 salas de aula, ambas pertencentes a uma escola estadual de ensino fundamental, em bairro residencial da cidade de Bauru, interior do estado de São Paulo.

Para a coleta dos dados, empregou-se, uma filmadora da marca Panasonic, modelo RJ 27. Optou-se pela filmagem em VT, já que esta estratégia de coleta de dados permite sua recuperação seqüencial, quantas vezes for necessária, para a efetivação da análise.

As filmagens foram realizadas no transcorrer do 1o semestre de um ano letivo. Foi necessário efetuar várias sessões de filmagem até que os participantes se habituassem com a presença da câmera e da pesquisadora, deixando de a elas responder.

Os dias para a filmagem foram sorteados, de modo que a professora não sabia em qual dia e horário a pesquisadora compareceria à sala de aula.

Definiu-se como interação "uma verbalização ou ação motora de um sujeito dirigida clara e diretamente a outro, seguida de verbalização ou de ação motora deste para o primeiro" (HINDE, 1979; CARVALHO, 1986; ARANHA, 1991). Considerou-se, um episódio um conjunto de interações que tratam de um mesmo assunto, o que passou a ser a unidade de análise (ARANHA, 1991).

A partir dessa definição, a análise dos dados percorreu 6 diferentes passos.

1 Elaboração de um sistema de categorias. Para descrever o contexto interativo entre professor e alunos, foi necessário assistir à filmagem inúmeras vezes, bem como considerar o que a literatura apresentava a respeito dessa temática, para, então, criar as categorias que permitissem a obtenção da resposta pretendida no objetivo do estudo. Assim sendo, chegou-se à constituição de um sistema de categorias: quem inicia, quem responde, como inicia, como responde, conteúdo, situação em que ocorre, orientação, quem interrompe e como interrompe. 
2 Elaboração das planilhas de registro. A fim de obter dados suficientes para descrever a interação entre professor e alunos, foi necessária a construção de planilhas de registro que tivessem campos para a descrição dos dados quanto ao conteúdo da interação, bem como quanto à qualidade da interação. Assim, as planilhas foram construídas de modo que nelas fosse possível registrar $\mathrm{O}$ QUE os sujeitos estão fazendo juntos e COMO o faziam juntos (HINDE, 1979).

3 Equalização temporal dos dados. Considerando que o tempo de filmagem diferiu de sessão para sessão, optou-se por adotar, como material para análise, o conteúdo coletado num período de tempo correspondente ao da sessão de menor duração. Buscou-se, assim, garantir, através do controle da variável tempo, a igualdade de oportunidades para ocorrência das interações. Assim, foi analisado o material coletado nos 10 primeiros minutos de cada sessão de coleta, na turma A, e nos 15 primeiros minutos de cada sessão na turma B.

4 Classificação dos episódios, nas categorias que constituíram o sistema de análise. À medida que se foi efetivando sua classificação, percebeu-se necessário acrescentar e/ou retirar algumas categorias, para que se pudesse realmente representar o conjunto de interações.

5 Participação de consultores na classificação das unidades de análise. Eles foram orientados pela pesquisadora sobre como deveriam proceder para classificar os episódios constantes da sessão de filmagem sorteada, bem como foram dadas as devidas instruções para preenchimento das planilhas de registro. $\mathrm{O}$ índice de concordância entre a pesquisadora e o consultor 1 , bem como entre a pesquisadora e o consultor 2 , foi de $50 \%$, mostrando-se abaixo do índice pretendido (85\%). A partir disto, o sistema foi revisto, focalizando especialmente as categorias que apresentavam maior índice de discordância (conteúdo, como inicia e como interrompe), reorganizando-as e tornando-as mais claras e objetivas. Posteriormente, solicitou-se aos mesmos consultores que classificassem novamente os episódios. Os índices de concordância, nessa segunda etapa, alcançaram o índice $100 \%$, o que indica que o sistema alcançou o nível desejado de clareza e objetividade.

6 Tratamento quantitativo e qualitativo dos dados. Finda a fase de classificação dos episódios, desenvolveu-se tratamento matemático, calculando-se as freqüências absolutas e as relativas dos dados constantes de cada categoria. Após o tratamento matemático, desenvolveu-se análise qualitativa, buscandose a compreensão do significado dos dados obtidos. 


\section{Resultados E Discussão} Turma A

A tabela 1 mostra as freqüências absolutas e relativas dos episódios interativos ocorridos a cada sessão. Estes ocorreram entre as díades professora $(\mathrm{P})$ e alunos não deficientes (A), professora (P) e alunos com deficiência mental (DM), professora $(\mathrm{P})$ e grupo $(\mathrm{G})$, alunos não deficientes $(\mathrm{A})$ e professora $(\mathrm{P})$, e alunos com deficiência mental (DM) e professora (P). Na tabela 3 encontram-se os dados obtidos, lembrando que a primeira letra indica o sujeito que iniciou a interação.

Tabela 1 - Identificação da frequiência de interação entre as diferentes díades, por sessão, da turma A

\begin{tabular}{c|c|c|cc|c|c|c|c|c|c|c|c}
\hline \multirow{2}{*}{$\begin{array}{c}\text { categoria } \\
\text { sessão }\end{array}$} & \multicolumn{2}{|c|}{ P-A } & \multicolumn{2}{c|}{ P-DM } & \multicolumn{2}{|c|}{ P-G } & \multicolumn{2}{|c|}{ A-P } & \multicolumn{2}{c|}{ DM-P } & \multicolumn{2}{|c}{ Total sessão } \\
\cline { 2 - 11 } & $\mathbf{f}$ & $\mathbf{\%}$ & $\mathbf{f}$ & $\mathbf{\%}$ & $\mathbf{f}$ & $\mathbf{\%}$ & $\mathbf{f}$ & $\mathbf{\%}$ & $\mathbf{f}$ & $\mathbf{\%}$ & $\mathbf{f}$ & $\mathbf{\%}$ \\
\hline $\mathbf{1}$ & 03 & $\mathbf{1 1}$ & 08 & $\mathbf{3 1}$ & 02 & $\mathbf{0 8}$ & 13 & $\mathbf{5 0}$ & 00 & $\mathbf{0 0}$ & 26 & $\mathbf{0 8}$ \\
$\mathbf{2}$ & 10 & $\mathbf{3 3}$ & 00 & $\mathbf{0 0}$ & 08 & $\mathbf{2 7}$ & 12 & $\mathbf{4 0}$ & 00 & $\mathbf{0 0}$ & 30 & $\mathbf{0 9}$ \\
$\mathbf{3}$ & 05 & $\mathbf{3 2}$ & 01 & $\mathbf{0 6}$ & 01 & $\mathbf{0 6}$ & 08 & $\mathbf{5 0}$ & 01 & $\mathbf{0 6}$ & 16 & $\mathbf{0 5}$ \\
$\mathbf{4}$ & 11 & $\mathbf{2 6}$ & 05 & $\mathbf{1 2}$ & 00 & $\mathbf{0 0}$ & 22 & $\mathbf{5 2}$ & 04 & $\mathbf{1 0}$ & 42 & $\mathbf{1 3}$ \\
$\mathbf{5}$ & 13 & $\mathbf{3 5}$ & 05 & $\mathbf{1 4}$ & 00 & $\mathbf{0 0}$ & 17 & $\mathbf{4 6}$ & 02 & $\mathbf{0 5}$ & 37 & $\mathbf{1 1}$ \\
$\mathbf{6}$ & 23 & $\mathbf{6 8}$ & 00 & $\mathbf{0 0}$ & 01 & $\mathbf{0 3}$ & 10 & $\mathbf{2 9}$ & 00 & $\mathbf{0 0}$ & 34 & $\mathbf{1 0}$ \\
$\mathbf{7}$ & 04 & $\mathbf{8}$ & 00 & $\mathbf{0 0}$ & 00 & $\mathbf{0 0}$ & 46 & $\mathbf{9 2}$ & 00 & $\mathbf{0 0}$ & 50 & $\mathbf{1 5}$ \\
$\mathbf{8}$ & 18 & $\mathbf{3 4}$ & 01 & $\mathbf{0 2}$ & 01 & $\mathbf{0 2}$ & 32 & $\mathbf{6 0}$ & 01 & $\mathbf{0 2}$ & 53 & $\mathbf{1 6}$ \\
$\mathbf{9}$ & 11 & $\mathbf{2 5}$ & 08 & $\mathbf{1 8}$ & 00 & $\mathbf{0 0}$ & 22 & $\mathbf{5 0}$ & 03 & $\mathbf{0 7}$ & 44 & $\mathbf{1 3}$ \\
Total & 98 & $\mathbf{3 0}$ & 28 & $\mathbf{0 8}$ & 13 & $\mathbf{0 4}$ & 182 & $\mathbf{5 5}$ & 11 & $\mathbf{0 3}$ & 332 & $\mathbf{1 0 0}$ \\
\hline
\end{tabular}

A maioria das interações ocorridas na turma $A$ foi iniciada por alunos não deficientes e dirigidas para a professora (55\%). A professora, por sua vez, iniciou $42 \%$ dos episódios.

Os resultados constatados neste estudo diferem dos de Bertoldo (1985), que afirmou que mesmo quando os alunos participam muito em sala de aula, a participação da professora como iniciadora dos contatos é maior.

Esta característica pode ser indicativa de que a professora desta turma permitiu, aos alunos, espaço para sua maior participação no processo de ensino e de aprendizagem.

Com relação ao aluno com deficiência mental, este iniciou 3\% dos episódios interativos ocorridos com a professora. 
Tais resultados mostraram-se consistentes com os de Macintosh et al. (1993), nos quais os alunos com dificuldades de aprendizagem interagiam em taxas inferiores a dos demais alunos. Este autor aponta ainda que a falta de individualização no ensino poderia estar determinando a menor participação do aluno com dificuldades, o que também pode ser verdadeiro neste estudo.

Por outro lado, Braga (2002), em estudo que investigou a interação entre a professora e um aluno autista, em sala inclusiva, constatou que o aluno autista iniciou mais contatos, com a professora, que o aluno não autista. Faz-se necessário, porém salientar que este dado parece ter ocorrido, nesse estudo, em função da sistemática de registro utilizada, que focalizava constantemente o aluno autista e não o aluno não autista.

A professora se dirigiu ao aluno com deficiência nas sessões 1, 3, 4, 5, 8 e 9. As sessões 1, 4, 5, e 9 foram aquelas nas quais a professora mais freqüentemente se dirigiu a ele, iniciando interação. Em ordem decrescente, constata-se que as iniciativas da professora, para interagir com esses alunos, ocorreram nas seguintes freqüências: $61 \%$ (1), $42 \%$ (9), 31\% (4), 28\% (5), 14\% (3), 5\%(8).

Por sua vez, o aluno com deficiência mental iniciou contato interativo com a professora, nas sessões 3,4,5,8 e 9, ou seja, na maioria das sessões em que esta também a ele se dirigiu.

Nas sessões 2, 6, e 7 a professora não iniciou contato com o aluno com deficiência nenhuma vez e ele também não iniciou contato com a professora nas sessões $1,2,6$, e 7 .

Considerando que, embora a professora não tenha interagido com os alunos com deficiência em 3 sessões, a mesma apresentou o maior número de iniciativas com o aluno com deficiência e isto pode, nessas sessões, tê-lo motivado a também tomar iniciativas de interação, no contexto da mútua determinação. Por outro lado, o fato do aluno com deficiência tomar iniciativas pode, também, ter motivado a professora a estabelecer contato interativo com ele.

Isto parece vir ao encontro do que Carvalho (1986) constatou em estudo que focalizou alunos não deficientes, no qual pôde demonstrar que o comportamento destes alunos influenciava de maneira diversificada o comportamento do professor e que a responsividade do professor era função do grau de participação destes alunos.

Esta influência também foi evidenciada por Gil (1991), quando afirmou que a participação dos alunos indicava uma relação de dependência com as ações da professora. Da mesma forma, Macintosh et al. (1993), referindo-se à baixa interação entre o professor e o aluno, comentou que o professor raramente interagia com o aluno com dificuldade de aprendizagem, padrão reproduzido também pelo aluno. 
Já com os alunos não deficientes, a professora iniciou contatos interativos em todas as sessões. Isto pode se explicar pelo número de alunos não deficientes na sala de aula, que excede, em muito, o número de alunos com deficiência, e do tempo de coleta que se mostra reduzido, quando comparado com o tempo total de aula diária.

Objetivando-se detectar padrões na interação entre a professora e os alunos com deficiência, e entre a professora e os alunos não deficientes, dividiu-se o número de episódios ocorridos, a cada sessão, entre a professora e o aluno não deficiente, pelo número de alunos não deficientes nela presentes, e o número de episódios ocorridos, a cada sessão, entre a professora e o aluno com deficiência, pelo número de alunos com deficiência, que estavam presentes na sessão. Com estes cálculos, a tabela 2 apresenta os índices obtidos.

Tabela 2 - Padrões da interação entre a professora e os alunos com deficiência e entre a professora e os alunos não deficientes.

\begin{tabular}{c|c|c}
$\begin{array}{c}\text { Número da sessão de } \\
\text { filmagem }\end{array}$ & Com aluno com deficiência mental & Com aluno não deficiente \\
\hline $\mathbf{1}$ & 4 episódios & 0,11 episódio \\
\hline $\mathbf{2}$ & 0 episódio & 0,34 episódio \\
\hline $\mathbf{3}$ & 0,5 episódio & 0,21 episódio \\
\hline $\mathbf{4}$ & 2,5 episódios & 0,42 episódio \\
\hline $\mathbf{5}$ & 2,5 episódios & 0,54 episódio \\
\hline $\mathbf{6}$ & 0 episódio & 0,88 episódio \\
\hline $\mathbf{7}$ & 0 episódio & 0,17 episódio \\
\hline $\mathbf{8}$ & 0,5 episódio & 0,78 episódio \\
\hline $\mathbf{9}$ & 4 episódios & 0,48 episódio
\end{tabular}

Este padrão reproduz o que Dorval, Mckinney e Feagans (1982), Slate e Saudargas (1986) descreveram: que a professora iniciava mais interações com os alunos que tinham dificuldades de aprendizagem, do que com os demais alunos da sala de aula, mesmo tratando-se de conteúdo para discriminar, repreender e punir estes alunos.

Por outro lado, esses índices contradizem o que foi posteriormente constatado por Macintosh et al. (1993), pois os autores concluíram que o professor raramente manifestou interação com os alunos com dificuldade de aprendizagem.

É interessante lembrar que estes resultados referem-se exclusivamente às sessões de coleta de dados, não sendo possível generalizá-los para todos os momentos da sala de aula. Assim, estes e os demais resultados dizem respeito a uma amostra, limitada, de como são as interações entre professor e alunos nesta turma. 
Na tabela 3 os episódios são classificados por sessão, segundo os conteúdos: indeterminado (IND), solicitação de atenção (SAT), solicitação de informação (SIN), prestação de informação (PIN), solicitação de ação (SAC), solicitação de objeto (SOB), oferecimento de objeto (OOB), repreensão (REP), ensino (ENS), elogio (ENS).

Tabela 3 - Classificação dos episódios por sessão, segundo os conteúdos

\begin{tabular}{|c|c|c|c|c|c|c|c|c|c|c|c|c|c|c|c|c|c|c|c|c|}
\hline \multirow{2}{*}{$\begin{array}{c}\text { categoria } \\
\text { sessão }\end{array}$} & \multicolumn{2}{|c|}{ IND } & \multicolumn{2}{|c|}{ SAT } & \multicolumn{2}{|c|}{ SIN } & \multicolumn{2}{|c|}{ PIN } & \multicolumn{2}{|c|}{ SAC } & \multicolumn{2}{|c|}{ SOB } & \multicolumn{2}{|c|}{ OOB } & \multicolumn{2}{|c|}{ REP } & \multicolumn{2}{|c|}{ ENS } & \multicolumn{2}{|c|}{ ELO } \\
\hline & f & $\%$ & f & $\%$ & f & $\%$ & f & $\%$ & f & $\%$ & f & $\%$ & f & $\%$ & f & $\%$ & f & $\%$ & f & $\%$ \\
\hline 1 & 04 & 15 & 02 & 08 & 05 & 19 & 01 & 04 & 05 & 19 & 00 & 00 & 01 & 04 & 00 & 00 & 07 & 27 & 01 & 04 \\
\hline 2 & 02 & 07 & 00 & 00 & 05 & 17 & 06 & 20 & 06 & 20 & 00 & 00 & 01 & 03 & 01 & 03 & 02 & 07 & 00 & 00 \\
\hline 3 & 02 & 13 & 08 & 50 & 02 & 13 & 00 & 00 & 01 & 06 & 01 & 06 & 00 & 00 & 01 & 06 & 00 & 00 & 00 & 00 \\
\hline 4 & 02 & 05 & 09 & 21 & 00 & 00 & 00 & 00 & 00 & 00 & 01 & 02 & 00 & 00 & 01 & 02 & 14 & 33 & 00 & 00 \\
\hline 5 & 03 & 08 & 04 & 11 & 05 & 14 & 04 & 11 & 00 & 00 & 00 & 00 & 00 & 00 & 05 & 14 & 08 & 04 & 00 & 00 \\
\hline 6 & 01 & 03 & 01 & 03 & 06 & 18 & 03 & 09 & 00 & 00 & 00 & 00 & 01 & 03 & 00 & 00 & 16 & 47 & 00 & 00 \\
\hline 7 & 03 & 06 & 09 & 18 & 22 & 44 & 09 & 18 & 02 & 04 & 00 & 00 & 01 & 02 & 01 & 02 & 01 & 02 & 00 & 00 \\
\hline 8 & 00 & 00 & 19 & 36 & 12 & 23 & 04 & 08 & 01 & 02 & 00 & 00 & 00 & 00 & 00 & 00 & 10 & 19 & 00 & 00 \\
\hline 9 & 01 & 02 & 03 & 07 & 13 & 30 & 05 & 11 & 02 & 05 & 00 & 00 & 02 & 05 & 02 & 05 & 08 & 18 & 00 & 00 \\
\hline Total & 18 & 5,4 & 55 & 17 & 70 & 21 & 32 & 10 & 17 & 05 & 02 & 01 & 06 & 02 & 11 & 3,3 & 66 & 20 & 01 & 0,3 \\
\hline
\end{tabular}

De todos os episódios ocorridos entre o aluno com deficiência mental - e a professora, $54 \%$ deles foram solicitação de atenção, distribuídos em 4 das 5 sessões em que o aluno com deficiência mental iniciou contatos com a professora. Foi na sessão 9 que ocorreram os conteúdos prestação de informação, solicitação de informação e ensino. Isto pode ter ocorrido dada a natureza da atividade desenvolvida nesta sessão, a saber, exercícios de Língua Portuguesa. Há ainda que se ressaltar que $100 \%$ das situações nas quais se constatou estes conteúdos ocorreram nos momentos em que a professora circulava pela sala de aula.

O conteúdo elogio esteve presente em $27 \%$ dos episódios, e o conteúdo ensino em outros $27 \%$. Já o conteúdo repreensão ocorreu uma única vez na sessão 5, representando $9 \%$ dos episódios. 
Diante desses dados, tem-se que entre o aluno com deficiência mental e a professora, as interações eram, predominantemente de solicitação de atenção, de elogio e de ensino, o que difere substancialmente do constante na literatura, que diz que o professor, ao interagir com o aluno com deficiência, o faz, para repreender (DORVAL, MCKINNEY e FEAGANS, 1982; SIPERSTEIN e GODING, 1985; SLATE e SAUDARGAS, 1986).

Entre a professora e o aluno com deficiência mental, o conteúdo ensino esteve presente em $57 \%$ dos episódios e ocorreu em 4 das 6 sessões em que esta díade interagiu. O conteúdo solicitação de informação foi identificado em $32 \%$ dos episódios e esteve presente em todas as sessões. Já o conteúdo elogio foi identificado em $14 \%$ dos episódios, e ocorreu em 3 das 6 sessões.

Diante desses dados, tem-se que entre a professora e o aluno com deficiência mental, as interações eram, predominantemente, de ensino, de solicitação de informação e de elogio.

Comparando os resultados obtidos entre as díades professora e o aluno com deficiência mental (quando a professora inicia a interação) e entre o aluno com deficiência mental e a professora (quando o aluno inicia a interação), tem-se que o aluno com deficiência, ao iniciar os episódios, utiliza com mais freqüência o conteúdo solicitação de atenção e o professor, ao iniciar os episódios, utiliza mais freqüentemente o conteúdo ensino.

Estes conteúdos não surpreendem, já que são os exigidos pelos papéis complementares que os diferentes sujeitos desempenham na sala de aula.

Os conteúdos ensino e elogio são freqüentes, independentemente de quem inicia a interação, e o conteúdo solicitação de atenção é característico somente quando o aluno inicia com o professor. Já o conteúdo solicitação de informação aparece preferencialmente quando o professor inicia com o aluno.

Estes dados mostram que a prática de ensino dessa professora é freqüente com os alunos com deficiência e que estes também a ela se dirigem para tratar as dúvidas que têm sobre o que está sendo ensinado. Aliado a isto, os elogios da professora para estes alunos ocorrem tanto quando ela, como quando eles iniciam a interação.

Comparando os índices das interações entre a professora e o aluno com deficiência mental e a professora e o aluno não deficiente, nota-se que o conteúdo ensino predomina em todas as iniciativas, o que parece ser positivo para todos os alunos, mas a professora solicita ação e repreende predominantemente aos alunos sem deficiência. O conteúdo elogio, por outro lado, apareceu em interações tanto com os alunos sem deficiência, quanto aos com deficiência mental, sendo, entretanto mais praticado com estes últimos. 
Nota-se, portanto, que com os alunos com deficiência mental as interações mais freqüentes são as que elogiam, as menos repreensivas e com menor freqüência de solicitação de ações do que com alunos não deficientes. Assim, a professora pede menos ações para os alunos com deficiência mental, elogia-os mais e os repreende menos.

Esses dados mostram-se divergentes com o que a literatura tem mencionado. Siperstein e Goding (1985) afirmam que as iniciativas e respostas do professor dirigidas ao aluno com deficiência eram mais negativas e corretivas do que com os estudantes não deficientes.

Dorval, Mckinney e Feagans (1982) igualmente observaram que as interações do professor dirigidas aos alunos com dificuldade de aprendizagem referiam-se à falta de atenção ou à infração de regras (por esses alunos).

Em se tratando de interações entre o professor e o aluno autista, Braga (2002) constatou conteúdos de repreensão, solicitação de informações, solicitação de ações, ensino e oferecimento de informações. Os conteúdos de ensino, solicitação de informação e mesmo o de repreensão, que foi inferior aos demais, coincidem com os identificados neste estudo, mas o conteúdo de solicitação de ação diverge com o que foi identificado, pois não houve solicitação de ação ao aluno com deficiência.

Os dados obtidos neste estudo, quando comparados com os constantes da literatura, mostram um movimento na direção de maior responsividade da parte da professora, para os alunos com deficiência. Além disso, mostra que o conteúdo parece ser mais positivo, de natureza reforçadora.

Isto pode sugerir uma mudança, ainda que incipiente, no padrão interativo entre professor e alunos, nos últimos anos.

\section{Turma B}

Considerando os episódios em vista de quem inicia e de quem responde, a tabela 4 mostra as freqüências absolutas e relativas dos episódios interativos constatados entre os sujeitos que interagiram em cada sessão. Estes ocorreram entre as díades: professora $(\mathrm{P})$ e aluno não deficiente $(\mathrm{A})$; professora $(\mathrm{P})$ e aluno com deficiência mental $(\mathrm{DM})$, professora $(\mathrm{P})$ e grupo $(\mathrm{G})$; aluno não deficiente $(\mathrm{A})$ e professora $(\mathrm{P})$, aluno com deficiência mental $(\mathrm{DM})$ e professora $(\mathrm{P})$, professora $(\mathrm{P})$ e aluno com deficiência auditiva e física (DAF), professora $(\mathrm{P})$ e aluno com deficiência mental e física (DMF), aluno com deficiência mental e física (DMF) e professora $(\mathrm{P})$ e aluno com deficiência auditiva e física $(\mathrm{DAF})$ e professora $(\mathrm{P})$. A primeira letra indica o sujeito que iniciou. 
Tabela 4 - Identificação da freqüência de interação entre as diferentes díades, por sessão.

\begin{tabular}{|c|c|c|c|c|c|c|c|c|c|c|c|c|c|c|c|c|c|c|c|}
\hline \multirow[t]{2}{*}{$\begin{array}{c}\text { categoria } \\
\text { sessão }\end{array}$} & \multicolumn{2}{|c|}{ P-A } & \multicolumn{2}{|c|}{ P-DM } & \multicolumn{2}{|c|}{$\begin{array}{c}\text { P- } \\
\text { DMF }\end{array}$} & \multicolumn{2}{|c|}{ P-DAF } & \multicolumn{2}{|c|}{ P-G } & A-P & \multicolumn{2}{|c|}{ DM-P } & \multicolumn{2}{|c|}{$\begin{array}{c}\text { DMF- } \\
\text { P }\end{array}$} & \multicolumn{2}{|c|}{ DAF-P } & \multicolumn{2}{|c|}{$\begin{array}{c}\text { Total } \\
\text { sessão }\end{array}$} \\
\hline & $\mathrm{f}$ & $\%$ & $f$ & $\%$ & $\mathrm{f}$ & $\%$ & $\mathrm{f}$ & $\%$ & $\mathrm{f}$ & $\%$ & $\%$ & $f$ & $\%$ & $\mathrm{f}$ & $\%$ & $\mathrm{f}$ & $\%$ & $\mathrm{f}$ & $\%$ \\
\hline 1 & 07 & 39 & 00 & 00 & 00 & 00 & 00 & 00 & 02 & 11 & $09 \quad \mathbf{5 0}$ & 00 & 00 & 00 & 00 & 00 & 00 & 18 & 08 \\
\hline 2 & 08 & 30 & 00 & 00 & 00 & 00 & 00 & 00 & 03 & 11 & $15 \quad 55$ & 01 & 04 & 00 & 00 & 00 & 00 & 27 & 12 \\
\hline 3 & 01 & 03 & 01 & 03 & 00 & 00 & 00 & 00 & 09 & 25 & $24 \quad 66$ & 01 & 03 & 00 & 00 & 00 & 00 & 36 & 16 \\
\hline 4 & 09 & 23 & 01 & 03 & 02 & 05 & 00 & 00 & 04 & 10 & 2154 & 00 & 00 & 02 & 05 & 00 & 00 & 39 & 18 \\
\hline 5 & 05 & 11 & 04 & 09 & 11 & 23 & 00 & 00 & 09 & 19 & $16 \quad 34$ & 02 & 04 & 00 & 00 & 00 & 00 & 47 & 21 \\
\hline 6 & 17 & 31 & 02 & 04 & 01 & 02 & 00 & 00 & 05 & 09 & $26 \quad 48$ & 03 & 06 & 00 & 00 & 00 & 00 & 54 & 25 \\
\hline Total & 47 & 21 & 08 & 04 & 14 & 06 & 00 & 00 & 32 & 15 & 11150 & 07 & 03 & 02 & 01 & 00 & 00 & 221 & 100 \\
\hline
\end{tabular}

$50 \%$ dos episódios interativos foram iniciados por alunos não deficientes, $46 \%$ foram iniciados pela professora e $4 \%$ dos episódios foram iniciados pelos alunos com deficiência.

Todos os episódios iniciados pelos alunos não deficientes e pelos alunos com deficiência foram dirigidos para a professora.

Dos episódios iniciados pela professora, $46 \%$ foram dirigidos para os alunos não deficientes, $8 \%$ dirigidos para o aluno com deficiência mental, 14\% dirigidos para o aluno com deficiência mental e física e $32 \%$ dirigidos para o grupo com um todo.

Estes resultados mostram-se semelhantes aos da turma A, uma vez que foram também alunos não deficientes que iniciaram a maioria dos episódios. Entretanto, na turma A, estes alunos iniciaram mais episódios (55\%) do que na turma B $(50 \%)$.

O fato de alunos não deficientes terem iniciado mais interações com a professora na turma $\mathrm{A}$, pode-se atribuir às idades destes alunos, que são inferiores aos da turma B. Estes se mostram mais inquietos e falantes, solicitando a todo o momento contato com a professora.

Objetivando-se detectar padrões na interação entre a professora e os alunos com deficiência, e entre a professora e os alunos não deficientes, dividiu-se o número de episódios ocorridos, a cada sessão, entre a professora $(\mathrm{P})$ e o aluno não deficiente (A), pelo número de alunos não deficiente $(\mathrm{A})$ nela presentes, e o número de episódios ocorridos, a cada sessão, entre a professora $(\mathrm{P})$ e o aluno com deficiência (DM e DMF), pelo número de alunos com deficiência (DM e DMF), que estavam presentes na sessão, conforme apresentado na tabela 5. 
Tabela 5 - Padrões da interação entre a professora e os alunos com deficiência e entre a professora e os alunos não deficientes.

\begin{tabular}{c|c|c|}
\hline $\begin{array}{c}\text { Número da sessão de } \\
\text { filmagem } \\
1\end{array}$ & $\begin{array}{c}\text { Com os alunos com deficiência (DM e } \\
\text { DMF) } \\
\text { 4 episódios }\end{array}$ & Com aluno não deficiente \\
\hline 2 & 0 episódio & 0,44 episódio \\
\hline 3 & 0,5 episódios & 0,47 episódio \\
\hline 4 & 1,5 episódios & 0,04 episódio \\
\hline 5 & 7,5 episódios & 0,39 episódio \\
\hline 6 & 7,33 episódios & 0,22 episódio \\
\hline
\end{tabular}

A professora se dirigiu ao aluno com deficiência mental nas sessões 3, 4, 5, e 6; ao aluno com deficiência mental e física nas sessões 4, 5 e 6, e não se dirigiu ao aluno com deficiência auditiva e física. A sessão 5 foi aquela na qual a professora mais se dirigiu aos alunos com deficiência mental e aos alunos com deficiência mental e física, iniciando contatos interativos.

O aluno com deficiência mental iniciou contato interativo com a professora, nas sessões 2, 3, 5 e 6, e o aluno com deficiência mental e física unicamente na sessão 4 . Considerando-se esses dados, observa-se que a iniciação de contatos da professora com esses alunos pode ter alguma influência nas respostas dirigidas a ela.

Da mesma forma que no estudo da turma A, quando a professora inicia contato com o aluno com deficiência mental, este tende também a iniciar contatos com ela.

Não diferiram os conteúdos das atividades realizadas, na turma B, com os alunos não deficientes e com os alunos com deficiência.

Comparando estes dados com os resultados obtidos com a turma A, observa-se que na turma $\mathrm{A}$ os conteúdos diferiram, quando se comparam as atividades realizadas com os alunos não deficientes e com os alunos com deficiência.

Entretanto, os resultados da turma A e B coincidem, à medida que caracterizam interações voltadas para o ensino e para a prestação de informação, e não somente para a repreensão e advertências aos alunos com deficiência. Sendo assim, os resultados de ambas as turmas mostram-se divergentes com o que a literatura tem mencionado, conforme discutido anteriormente, na turma A.

A orientação das atividades ocorridas na turma A e na turma B, mostram-se diferentes. Na turma $\mathrm{A}$, conforme mencionado, a orientação não voltada para a tarefa ocorreu somente com os alunos não deficientes; já nesta turma, ocorreu tanto com os alunos não deficientes, quanto com os alunos com deficiência mental. 
Os resultados da turma B, da mesma forma que o constatado na turma A, diferem dos obtidos nos estudos de Bertoldo (1985), Carvalho (1986), e Braga (2002).

Considerando que estes autores constataram que as interações que os alunos iniciam com a professora são freqüentemente voltadas para atividades não relacionadas à tarefa escolar, pode-se formular a hipótese de que, neste estudo, os episódios iniciados pelos alunos tenham sido preferencialmente voltados para a tarefa, devido à falta de oportunidades oferecidas para que tivesse sido o contrário, podendo estar relacionados com a atitude pedagógica da professora em sala de aula, especialmente a da turma A.

Os resultados mostraram, em ambas as turmas, as seguintes tendências:

- O número de episódios interativos não parece ser função do número de alunos presentes na sala de aula, tampouco dos dias da semana;

- É o aluno não deficiente quem mais inicia episódios interativos dirigidos para a professora;

- As iniciativas de interação da professora, dirigidas aos alunos com deficiência, parecem ter influência na freqüência das interações destes alunos com ela e vice-versa;

- A comunicação verbal e visual é a mais utilizada para iniciar, responder e interromper os episódios interativos;

- São os alunos não deficientes os que mais respondem a interação através da comunicação visual e gestual;

- A maioria das interações é de conteúdo ensino e prestação de informação;

- As atividades voltadas para a tarefa são mais freqüentes do que as não voltadas para a tarefa, tanto quando a professora inicia o episódio, como quando o aluno inicia o episódio;

- A professora é quem predominantemente interrompe os episódios interativos, independentemente de quem inicia;

- A professora predominantemente inicia mais episódios interativos com o aluno com deficiência do que com o aluno não deficiente;

- Os episódios interativos com os alunos com deficiência nunca são interrompidos por eles mesmos e sim pelos alunos não deficientes ou pela professora; 
- A maioria das interações entre a professora e os alunos com deficiência mental ocorre quando a professora está circulando pela sala de aula.

Por outro lado, as turmas diferem nos seguintes aspectos:

- Na turma B, o horário de coleta parece exercer alguma influência nos resultados obtidos, uma vez que se evidenciou um aumento no número de episódios à medida que o horário da sessão era mais próximo do final da aula;

- Na turma B, houve um maior número de interação da professora com os alunos com deficiência e com o grupo do que na turma A;

- Na turma B, as interações da professora dirigidas aos alunos com deficiência mostram-se praticamente com os mesmos conteúdos identificados com os alunos não deficientes;

- Na turma A, a comunicação visual e gestual foi mais utilizada para iniciar episódios interativos do que na turma B;

- Na turma A, as interações da professora dirigidas aos alunos com deficiência, são menos repreensivas, com menos solicitações de ações e mais elogiadas, do que com os alunos não deficientes;

- Na turma A, os episódios ocorreram, com maior freqüência, na situação de quando a professora estava circulando entre as carteiras (com todos os alunos) e na turma B, a predominância das interações quando a professora está circulando entre as carteiras se refere apenas aos alunos com deficiência; com os demais alunos há preferência pela situação de quando a professora está em sua mesa conferindo tarefas.

\section{CONCLUSÃO}

Diferentemente do identificado por Macintosh et al. (1993), este estudo constata que as professoras mantiveram interações diferentes com os dois grupos de alunos (deficientes e não deficientes), na maioria das categorias analisadas.

As ações das professoras parecem estar propiciando maior espaço de participação dos alunos, nas aulas, especialmente no caso dos alunos com deficiência, o que constitui um avanço educacional, quando se tomam por parâmetro, as informações constantes da literatura na área (DORVAL, MCKINNEY e FEAGANS, 1982; SIPERSTEIN e GODING, 1985; SLATE e SAUDARGAS, 1986 e MACINTOSH et al. 1993) que mostram o aluno com deficiência historicamente relegado ao ostracismo e à gradativa exclusão do sistema regular de ensino. 
Neste estudo, o aluno não deficiente iniciou a maioria das interações, fato que também difere da literatura a respeito (BERTOLDO, 1985). As professoras, por sua vez, iniciaram mais interações com os alunos deficientes do que com os não deficientes, sendo essas interações, na sua maioria, de conteúdo ensino, elogio e solicitação de informação. Essa característica da relação entre as professoras e os alunos com deficiência, quando comparada com as informações da literatura, mostra ser mais positiva e condizente com o papel que a professora deve assumir em sala de aula, o de ser, segundo Duarte (1993), condutora do processo de apropriação, pelos alunos, do conhecimento produzido histórica e socialmente.

Ações desse tipo ajudam no próprio processo de construção de uma identidade positiva por parte de todos alunos, aumentando sua auto-estima, melhorando as suas condições cognitivas, e por outro lado, ajudando o aluno não deficiente a aprender a se relacionar positivamente com as pessoas no contexto da diversidade.

Os conteúdos diferenciados que a professora da turma A realizou com os alunos e o maior número de interações realizadas pela professora da turma $B$ com estes alunos, mostram indícios de que ambas estão se voltando mais (do que a literatura aponta) para o aluno com deficiência, cada uma do seu jeito.

Segundo os autores, Dorval, Mckinney e Feagans (1982), Siperstein e Goding (1985), Slate e Saudargas (1986), as interações da professora com o aluno com dificuldade de aprendizagem se referiam à falta de atenção ou infração de regras, além de serem mais negativas e corretivas do que com os alunos não deficientes. Este dado mostra-nos indícios de um avanço que nessas turmas demonstra estar ocorrendo, considerando o que, até o momento, foi constatado na área educacional através da literatura.

Em se tratando dos alunos com deficiência, constata-se que estes iniciam interações com a professora para solicitarem a sua atenção nas atividades que realizam e para solicitarem informações sobre o conteúdo da aula. Este dado, quando comparado aos de Macintosh et al. (1993), mostra que estes alunos estão tendo a oportunidade de se mostrarem mais ativos e participativos na sala de aula e principalmente na construção do conhecimento. As oportunidades que lhe estão sendo propiciadas, para que possam demonstrar essas características nas interações em sala de aula, merecem destaque pela sua importância quando consideramos que a formação do indivíduo se dá através das relações sociais.

Segundo Vygotsky (1994), as funções psicológicas superiores que caracterizam essencialmente o ser humano, originam-se das relações sociais entre os indivíduos. O fato de estar havendo espaço e, além disto, solicitação aos alunos para que iniciem interações e respondam a elas quando solicitados, favorece a participação de alunos no contexto regular da sala de aula, e, assim, um possível e melhor desenvolvimento destes alunos. 
Se avanços na atenção ao aluno com deficiência podem ser constatados a partir destes resultados, não se pode, entretanto, dizer que as salas aqui estudadas sejam salas inclusivas, pois, apesar do avanço atitudinal e mesmo metodológico observados, ainda não se pôde detectar a prática do ensino individualizado e flexível.

A interação nas duas salas de aula pesquisadas mostra a necessidade da professora assistir mais freqüentemente às necessidades individuais dos alunos não deficientes, não os mantendo ignorados na ocorrência de comportamentos inadequados, que merecem repreensão e solicitação freqüentes, conforme visto.

A abertura de espaço para tais comportamentos também pode estar interferindo no próprio processo de ensino e de aprendizagem, que tende a tornarse mais desestimulante, à medida que o aluno não recebe resposta à sua necessidade escolar e fica preterido nas relações em sala de aula.

Além disso, a comunicação de que as professoras fazem uso para iniciar, responder e interromper as interações precisa ser transformada, pois se mostra praticamente igual para todos os alunos, não se mostrando específica para as necessidades peculiares de cada um.

Finalizando, a maior contribuição deste estudo foi a de indicar que a interação entre a professora e os alunos, nas duas salas de aula, testemunha avanços na área educacional, no que diz respeito à atenção ao aluno com deficiência, embora ainda se manifeste distante de merecer o rótulo de educação inclusiva, ou seja, uma prática educacional que reconheça, respeite e responda às necessidades peculiares de cada aluno.

\section{REFERÊNCIAS}

ARANHA, M.S.F. A interação social e o desenvolvimento de relações interpessoais do deficiente em ambiente integrado. 1991. Tese (Doutorado) - Instituto de Psicologia. Universidade de São Paulo, São Paulo.

. Paradigmas da relação da sociedade com as pessoas com deficiência. Revista do Ministério Público do Trabalho, ano XI, n. 21, março, p.160-173, 2002.

ARANHA, M.S.F., LARANJEIRA, M.I. Brasil, século XX, última década. Mímeo, 1995.

BERTOLDO, A.A. Estudo descritivo da interação professora - aluno em uma classe de alfabetização em diferentes momentos do ano letivo. 1985. Dissertação (Mestrado), Universidade Federal de São Carlos, São Carlos.

BONETI, R.V.F. O papel da escola na inclusão social do deficiente mental. In: MANTOAN, M.T.E. A integração de pessoas com deficiência: contribuições para uma reflexão sobre o tema. São Paulo: Memnon, 1997. p. 167-173. 
BRAGA, M.C.B. A interação professor-aluno em classe inclusiva: um estudo exploratório com criança autista. 2002. Dissertação (Mestrado em Educação), Universidade Estadual Paulista, Marília.

BRASIL. Secretaria de Educação Fundamental. Parâmetros Curriculares Nacionais: Adaptações Curriculares / Secretaria de Educação Fundamental. Secretaria de Educação Especial. - Brasília: MEC / SEF / SEESP, 1999.

CARVALHO, A.M.P. Estudo descritivo da interação professor-aluno: uma abordagem individualizada. 1986. Dissertação (Mestrado em Educação Especial), Universidade Federal de São Carlos, São Carlos.

DORVAL,B.; MCKINNEY,J.D.; FEAGANS,L. Teacher interaction with learning disabled children and average achievers. Journal of Pediatric Psychology, 7, 317-330, 1982.

DUARTE, N.A individualidade para - si. Contribuição a uma teoria histórico-social da formação do indivíduo. Campinas: Autores Associados, 1993.

GIL, M.S.C.A. Análise funcional da interação professor-aluno: um exercício de identificação de controle recíprocos. 1990. Tese (Doutorado em Psicologia Educacional) - Instituto de Psicologia, Universidade de São Paulo, São Paulo.

HINDE, R.A. Towards understanding relationships. New York: Academic Press Incorporation, 1979.

LEONTIEV, A.N. O desenvolvimento do psiquismo. Lisboa: Livros Horizonte, 1978.

MACHADO, V.L.M. Aprendizagem e interação professor-aluno. In: WITTER, G. P.; LOMÔNACO, J.F.B. (Org.). Psicologia da aprendizagem: aplicações na escola. São Paulo: EPU, 1987.

MCINTOSH, R. et al. Observations of students with learning disabilities en general education classrooms. Exceptional Children, v. 60, n. 3, p. 249-261, Dec/Jan. 1993.

MELLO, A.M.S.R. Autismo e Integração. In: MANTOAN, M. T. E. A integração de pessoas com deficiência: contribuições para uma reflexão sobre o tema. São Paulo: Memnon, 1997. p. 13-17.

SALVADOR, C. C. Aprendizagem escolar e construção de conhecimento. Porto Alegre: Artes Médicas, 1994.

SAVIANI, D. Pedagogia histórico-crítica: primeiras aproximações. São Paulo: Cortez, 1991.

SILVA, S.C. Interação entre professora e alunos em sala inclusiva. 2003. Dissertação (Mestrado em Educação) - Universidade Estadual Paulista Júlio de Mesquita Filho - UNESP, Marília. 
SIPERSTEIN, G.N.; GODING, M.J. Teachers behavior toward LD and Non-LD children: A strategy for change. Journal of Learning Disabilities, v. 23, p. 32-37, 1985.

SLATE, J.R.; SAUDARGAS, R.A. Differences in learning disabled and average students classroom behaviors. Learning Disability Quarterly, v. 9, p. 61-67, 1986.

VYGOTSKY, L. A formação social da mente. São Paulo: Martins Fontes, 1994.

Recebido em 03/08/2005

Reformulado em 22/11/2005

Aceito em 22/12/2005 